\title{
Introducción a la doctrina cooperativa: perspectiva histórica y doctrinal
}

\author{
José María Vaquero Sánchez \\ Doctor en Derecho \\ GSD Cooperativa
}

Sumario: 1. Introducción: antecedentes doctrinales y lucha contra la usura. 2. Inspiradores de la doctrina cooperativa en general: Owen, Fourier y Saint-Simon. 3. Ramificaciones del ideal cooperativo. 4. Marxismo, cooperativismo y catolicismo: Gide, Pfeiffer, Staudinger. 5. Rochdale y los principios cooperativos: breve recorrido hasta nuestros días.

Resumen: El objetivo del artículo es mostrar la aparición doctrinal de los principios cooperativos a partir de la obra, reflexiones y propuestas empresariales de sus principales actores a lo largo de la historia del movimiento. Se parte de una reflexión general sobre el lucro y la usura en el contexto de la polémica entre luteranismo y catolicismo, con la figura de Luis de Molina como eje vertebrador de la misma. Los resultados de esta polémica junto al posterior desarrollo jurídico e ideológico de la Revolución Francesa servirán de telón de fondo para el desarrollo de la doctrina cooperativa.

Palabras clave: Cooperativismo, capital, usura, marxismo, lucro, cristianismo

Abstract: The main purpose of this article is to show the doctrinal approach to the main cooperative principles based on work, thoughts and corporate offers of the main actors along with the movement history. Its origins come from a deep thought about profits and usury in the polemic Lutheranist and the Catholicist context in which Luis de Molina contitutes the backbone. The results together with the legal and ideological development of the French Revolution will be the background for the cooperative doctrine development.

Keywords: Cooperativism, capital, usury, marxism, profit, christianity. 


\section{Introducción: antecedentes doctrinales y lucha contra la usura}

Nos proponemos en este artículo mostrar las líneas generales del desarrollo histórico del movimiento cooperativo. A la vez, y como si del desarrollo de un papiro se tratase, irán apareciendo las cuestiones doctrinales en forma de principios o fundamentos de la doctrina. La perspectiva es doble: histórica y doctrinal. Nuestra intención general es que se pueda observar, de una manera didáctica, el origen histórico los principios que irán apareciendo como resultado de las teorizaciones, prácticas (algunas veces conscientes y otras no), circunstancias sociales, políticas, económicas en las que está envuelto el movimiento.

Como veremos en detalle, el movimiento cooperativo es fruto de una reacción de las clases populares (o miembros de las mismas) ante las condiciones generadas por la sociedad capitalista, en concreto, la que se produce a lo largo del siglo XIX ${ }^{1}$. Ahora bien, que el detonante aparezca en la sociedad industrial, no niega que existan antecedentes del mismo. Es más, probablemente el movimiento no habría cristalizado si no existiesen estos antecedentes teóricos, doctrinales o filosóficos.

Desde nuestro punto de vista, y a riesgo de establecer quizá una tesis demasiado arriesgada, pensamos que uno de los precursores más importante de la doctrina cooperativa es el jesuita español Luis de Molina (Cuenca, 1535). Su polémica o reacción frente a la doctrina protestante del fatalismo en el siglo XVI, prefigura las ideas generales de la doctrina cooperativa. En concreto, su teoría sobre el precio justo y el beneficio es una consecuencia de su concepción sobre el lucro y la usura frente al determinismo protestante.

La obra de Molina se sitúa en el contexto histórico del Concilio de Trento (1554-1563) y sus desarrollos teóricos y teológicos frente a la doctrina luterana. En concreto, el protagonismo de Molina se va a producir en el desarrollo de la polémica de auxilis (1582-1607) donde, entre otros asuntos, se discute la doctrina de la libertad humana. Molina establece su posición al respecto en su obra Concordia liberi arbitrii cum gratiae donis ${ }^{2}$. La doctrina luterana defendía la predestinación,

1 «El cooperativismo nació en el mismo medio social, en la misma época, de la miseria proletaria y de la misma opresión, bajo el impulso del mismo espíritu que el sindicalismo y el socialismo. expresa las mismas profundas aspiraciones y la misma concepción de la vida». LASSERRE, G., El cooperativismo, Ed. Oikos-tau, Barcelona, 1972, pág. 11.

2 Resulta muy interesante, aunque excede por completo los límites de este trabajo, la consideración de los antecedentes con respecto a la libertad humana de Francisco Suarez (Granada, 1548) donde, basándose en las reglas de los Ejercicios Espirituales de San Ignacio se posiciona frente a la doctrina luterana de la predestinación. «No debemos hablar mucho de la predestinación por vía de costumbre; mas si en alguna manera 
es decir, la determinación del destino o lugar de cada hombre en el mundo por la gracia divina. Por tanto, su condición social obedece, en última instancia, a la voluntad divina.

Como consecuencia inmediata de esta posición, la doctrina luterana negará la libertad humana pues, en el límite, nadie puede ir en contra del lugar que, por gracia divina, le corresponde ocupar ${ }^{3}$. De esta manera, queda legitimado por vía teológica el orden social jerárquico e inamovible que, entre otros, favorecía la posición de poder de los príncipes o gobernantes que se acogieran a la doctrina luterana. La reacción de Luis de Molina no se hizo esperar y frente al luteranismo, fue un firme defensor de la acción libre del hombre en virtud de su naturaleza racional de origen aristotélico, negando la predestinación. El orden social debe estar establecido por acuerdo de los hombres pudiendo estos subvertirlo si es contrario al bien común ${ }^{4}$.

La doctrina luterana, al descender a asuntos de carácter económico, se muestra partidaria del lucro (usura) y afirma que no es contrario a la ley divina si dichos bienes usurpados están encaminados a honrar a Dios y no a los placeres del cuerpo ${ }^{5}$. La posición de Molina con

y algunas veces se hablare, asi se hable que el pueblo menudo no venga en error alguno, como a veces suele diciendo: si tengo que ser salvo o condenado, ya está determinado, y por mi bien hacer o mal no puede ser ya otra cosa; y con esto entorpeciendo se descuidan en las obras que conducen a la salud y provecho espiritual de sus ánimas» (Regla 15). Para consideraciones más profundase véase la magnífica introducción de Juan Antonio Hevia Echeverría en BÁÑEZ, D., Apología de los hermanos dominicos contra la Concordia de Luis de Molina, Ed. Pentalfa, Oviedo, 2002.

3 "Nadie puede dudar de que [los gobernantes o los campesinos] están en el mundo por la voluntad y el orden de Dios». LUTERO, M., Escritos políticos, Ed. Tecnos, Madrid, 1986, pág. 25.

4 Santo Tomás establece que es lícita la rebelión en dos casos, ex defecto titutli, cuando el gobernante no es apto para tal cometido y a regimene, es decir, cuando existe el abuso de poder. Siguiendo la línea tomista se encuentra Francisco Suarez quien llega a establecer la legitimidad de la rebelión frente a un orden social o político injusto que no se encamine al bien común: "aun cuando esta potestad sea como una propiedad natural de la comunidad perfecta de hombres, no obstante, no están en ella inmudablemente, sino que por consentimiento de la misma comunidad o por otra justa vía puede privarse de ella y transferida a otro», SUAREZ, F., De legibus, CSIC, Madrid, 1981, Libro III, cap. IV, 1.

5 «Podéis trabajar para ser ricos, no para poner luego vuestra riqueza al servicio de vuestra sensualidad y vuestros pecados, sino para honrar a Dios con ella. La riqueza es reprobable solo cuando incita a la pereza corrompida y al goce sensual de la vida; el deseo de enriquecerse solo es malo cuando tiene por fin asegurarse una vida despreocupada y cómoda y el goce de todos los placeres; pero, como ejercicio del deber profesional, no solo es éticamente lícito, sino que constituye un precepto obligatorio», WEBER, M., La ética protestante y el espíritu del capitalismo, Ed. Península, Barcelona, 1988, pág. 225. 
respecto al lucro, intereses y precio justo es totalmente opuesta a la del luteranismo. En su conocida Disputa 320 del Tratado sobre los préstamos y la usura, Molina establece que la usura debe prohibirse y penalizarse precisamente por ser contraria a la ley; es cierto que Luis de Molina reconoce que la usura puede darse en determinadas circunstancias sin ser contraria a la ley natural. Puede exigirse una parte que supere lo prestado para garantizar la seguridad de la deuda que contrae el prestatario, pero esta debe adecuarse precisamente a esa garantía y, por lo tanto, no ser objeto de lucro. Así, no niega Molina la existencia de «intereses», pero solo en la medida en que estos no produzcan un beneficio más allá de la propia seguridad de pago del préstamo, u otras circunstancias excepcionales, pues de lo contrario se estaría incurriendo en usura ${ }^{6}$.

La perspectiva molinista prefigura en el tiempo las consideraciones que en el siglo XIX van a defender los creadores de las primeras cooperativas. Es precursora de la posición con respecto al trabajo y el capital que defenderá el marxismo, para el que la acción humana libre y productiva genera el valor de las cosas; la apropiación sobre los beneficios debe encaminarse al bien común. Esa acción libre, en la tradición aristotélico-tomista en que la que se sitúa Luis de Molina, determinará la posición social del hombre en la sociedad y no al revés, como establece Lutero.

Al igual que hemos visto en el molinismo una prefiguración de las ideas cooperativas, situamos como antecedente político de las mismas a la Revolución Francesa. En una primera aproximación, la revolución supuso, en principio, el triunfo de las clases populares frente al antiguo régimen. Estableció un catálogo fundamental de Derechos (Derechos del Hombre y del Ciudadano) y, en concreto, a través de la Ley Le Chapelier (1791) la libertad de asociación y de empresa, destruyendo la antigua endogamia atribuida a los gremios. De igual manera, la ley estableció la posibilidad de que cualquier persona pudiese iniciar cualquier tipo de actividad empresarial libremente. Ahora bien, a pesar del gran avance social propiciado por estas medidas, la defensa inalienable de la propiedad privada y la libertad económica supusieron la generación de una sociedad profundamente dividida en clases sociales y la instauración de un orden económico liberal-capitalista.

6 De hecho, al menos de forma teórica, una de las consecuencias inmediatas del Concilio de Trento fue el decrecimiento de las rentas de los eclesiásticos: «las viejas prácticas financieras, que tanto dieron de hablar en los tiempos de Aviñon, expectancias, regresiones, accesiones, etc., fueron simplemente abolidas () el Papa estuvo totalmente de acuerdo en que tanto él como la curia perdieran con este motivo una gran parte de sus rentas». HERTLING, L., Historia de la Iglesia, Ed. Herder, Barcelona, 1993, pág. 347. 
La Revolución Industrial, el liberalismo económico y la aparición de nuevas ciencias contribuyeron indudablemente a la mejora productiva. Ahora bien, ese mismo sistema que alcanza la mayor producción industrial de la historia, generó una sociedad profundamente fracturada en clases sociales económicamente muy distanciadas.

De nuevo, y a pesar de los innegables avances para las clases populares, el lucro vuele a establecerse en el siglo xix bajo el modo de producción capitalista que, esencialmente, reproduce el esquema denunciado por Molina, aunque en este caso, a escala industrial. Así lo muestra precisamente Max Weber cuando afirma que el espíritu del capitalismo tiene su génesis en la doctrina protestante para la que el lucro no es contrario a ley divina si se produce para honrar a Dios y no a los placeres del cuerpo, como hemos indicado anteriormente.

En el siglo XIX, el capitalismo tiene como esencia la generación infinita, recurrente y circular de capital. La puesta de este en el mercado multiplica flujos de capital que sirven para satisfacer la dinámica del propio sistema de mercado que lo produce: el «lucro» es la esencia de la vida del sistema capitalista7. El lucro, legítimo teológicamente para el protestantismo, forma parte sustancial del espíritu del capitalismo y frente a él (de nuevo una reacción) se van a situar el catolicismo, el cooperativismo y el marxismo; cada uno, desde sus principios, se posicionarán frene el lucro inherente al modo de producción capitalista ${ }^{8}$. A

7 De las diferentes caracterizaciones del capitalismo realizadas desde hace un siglo y medio retendremos una fórmula mínima que hace hincapié en la exigencia de acumulación ilimitada de capital mediante medios formalmente pacíficos. La perpetua puesta en circulación del capital dentro del circuito económico con el objetivo de extraer beneficios, es decir, de incrementar el capital que será a su vez reinvertido de nuevo, sería lo que caracterizaría primordialmente al capitalismo [...] las formas concretas de la riqueza no tienen interés en sí y pueden suponer incluso, debido a su falta de liquidez, un obstáculo para el único objetivo realmente importante: la transformación permanente del capital, de los bienes de equipo y de las distintas adquisiciones en producción, de la producción en dinero y del dinero en nuevas inversiones», BOLTANSKI, L. \& CHIAPELLO, E.: El nuevo espíritu del capitalismo, Ed. Akal, Madrid, 2002, pág. 35.

8 El tema de los fundamentos de las doctrinas resulta muy interesante pero excede los límites de este trabajo. Citamos a continuación la posición de Antonio Gascón y Miramón donde, donde se equipara el lucro de la sociedad capitalista con el demonio. Evidentemente, desde posiciones marxistas estos fundamentos serían negados pues el ateísmo es uno de los fundamentos de la doctrina. Como decimos, un estudio sobre los principios resultaría del mayor interés: "donde la actividad se encamina a lograr lo que propiamente se llama lucro, no habría cooperación. El espíritu cooperativo y la idea de lucro no caben juntos en ninguna parte. Cuando una cooperativa se deja tentar por el demonio de la especulación y de la ganancia, se desnaturaliza, decae; y la mayor parte de las veces se muere, si no se limpia a tiempo del pecado». GASCÓN Y MIRAMÓN, A., La cooperación y las cooperativas, Madrid, 1954, págs. 10-11 
pesar de sus diferencias evidentes en cuanto a sus puntos de partida, las tres doctrinas (catolicismo, marxismo y cooperativismo) establecen una crítica general a los fundamentos, y la fractura social generada por ellos, del capitalismo o liberalismo económico.

El catolicismo, a pesar de mostrarse partidario de la propiedad privada, establece que el límite de la misma está condicionada al bien común, a los bienes comunes de los que hablaba Francisco de Vitoria9; el marxismo plantea frontalmente la supresión de la propiedad privada y la instauración de una sociedad sin clases (comunismo); el cooperativismo establece que la contradicción entre capital y trabajo se resuelve con la propiedad común (comunitaria) del medio de producción convirtiendo al trabajador en propietario y a este en trabajador en igualdad de condiciones.

\section{Inspiradores de la doctrina cooperativa en general: Owen, Fourier y Saint-Simon}

La actividad cooperativa o colaborativa hunde sus raíces en lo más profundo de la naturaleza de las especies. La cooperación es un mecanismo de la evolución de las especies que bajo la forma de «ayuda mutua», tal y como observó Kropotkin, desarrollan estrategias conjuntas de supervivencia frente a otras especies. De este modo, la cooperación entre miembros de una misma especie da como resultado un mecanismo de defensa frente a los riesgos (alimenticios, supervivenciales...) a los que la historia evolutiva somete a los organismos. Ahora bien, el origen de estas estrategias cooperativas, al igual que la posición de Molina frente al protestantismo, es fruto de una reacción frente a una amenaza.

El origen de las primeras consideraciones teóricas acerca del cooperativismo es fruto de esta situación dialéctica. La perspectiva de los precursores de la doctrina cooperativa es una reacción defensiva que se si-

9 «el dominium ómnium natural de cada persona no ha sido derogado sino sigue siendo válido en la tierra, teniendo con ello los hombres un dominium omnium y, por tanto, siendo libres e iguales por derecho natural. Este dominium omnium aparece o cobra validez en dos situaciones particulares. La primera, en los derechosde caza, pesca y provisión de leña, que sólo deben ser limitados por razones justificables; y la segunda, cuando alguien pierde sus bienes o se encuentra enestado de extrema necesidad — «In extrema necessitate omnia sunt communia»- y conduce a un derecho natural del necesitado de tomar lo necesario para cubrir sus necesidades. AÑANOS MEZA, M., "La doctrina de los bienes comunes de Francisco de Vitoria como fundamentación del dominio en el Nuevo Mundo», persona y derecho, vol. 68, 2013,1, 103-137 103, ISSN 0211 4526, págs. 114-115 
túa, dialécticamente, frente a los abusos o excesos que, con respecto al hombre, surgen en la sociedad liberal-capitalista decimonónica. El cooperativismo es una respuesta o reacción frente a una amenaza que un determinado régimen económico-político ha generado: la cosificación del individuo humano en el proceso productivo capitalista.

El cooperativismo, por tanto, se desarrolla en una doble dimensión (empresarial y ética) heredera, en último término, de las posiciones de Luis de Molina frente al lucro. Los hombres no deben aprovecharse de otros hombres (la explotación del hombre sobre el hombre tiene su origen en Saint-Simon) y desde esta perspectiva analizaremos a los precursores teóricos de la doctrina cooperativa.

Robert Owen (Newtown, 1771) es, sin lugar a dudas, uno de los padres de la doctrina cooperativa ${ }^{10}$. Nacido en Gales, e influido ideológicamente por las ideas ilustradas (Diderot, D’Alambert, Rousseau...) pronto se mudó a Manchester donde rápidamente se convirtió en millonario por la gestión de la empresa New Lanark. Sin embargo, para Owen, el éxito económico no debía estar reñido con el éxito social de los miembros de la fábrica. Es más, el éxito empresarial no es tal si no se relaciona con el bienestar de los trabajadores. De este modo, y a pesar de la financiación privada de la fábrica, Owen destinaba los beneficios de la misma (además de retribuir a los accionistas) a satisfacer las necesidades básicas de los trabajadores.

La fábrica, para Owen, debe ser un entorno que satisfaga y potencie todas las necesidades sociales de los trabajadores. Así, garantizar las condiciones de vida (educación, vivienda, higiene ) es el retorno que deben tener los trabajadores por su participación en el proceso productivo ${ }^{11}$.

10 "Antes de Rochdale, es decir, antes de que los Pioneros de Rochdale fundaran su sociedad en 1848, todas las cuestiones que habría de plantearse la doctrina cooperativa, incluso las más actuales, habian sido consideradas en una obra rica y compleja, que va de Robert Owen a Louis Blanc. Defenderé contra algunos cooperadores la tradición que hace de Fourier y de Owen los padres de la cooperación. A decir verdad ninguno de los dos teóricos trazó con detalle las formas que después tomaría la cooperación, pero uno y otro afirmaron los principios fundamentales sobre los que se desarrollaría», LAMBERT, Paul, La doctrina cooperativa, Ed. Intercoop, Buenos Aires, 1975, pág. 18

11 «New Lanark fue conocida en todo el mundo como uno de los primeros experimentos de crear un entorno de trabajo y unas condiciones de vida aceptables para la población trabajadora, sin apartarse del proceso industrial de mecanización a gran escala. Aparte de la escuela, se construyeron viviendas mejores para los trabajadores y sus familias, con iluminación por gas, y condiciones higiénicas cuidadas. Owen mejoró las tiendas, lo que se tradujo, nos dice con su habitual precisión, en una mejora visible de su salud y de su vestimenta: ahorraron el $25 \%$ de sus gastos y mejoró la calidad de la mercancía. Pero la confianza de los trabajadores se la ganó Owen en una situación más dramática: en 1806 Estados Unidos suspendió sus exportaciones de algodón por una crisis diplomática. 
Bajo esta concepción general del trabajo, ideó las «aldeas cooperativas» donde toda la vida giraba en torno a los beneficios productivos que eran fruto del trabajo. Owen, cada vez más convencido de la justicia de sus planteamientos, se dedicó o promulgar sus ideas más allá de su experiencia como gestor empresarial. Así, al final de su vida intentó implantar su modelo en diferentes lugares del planeta. Más allá del éxito o no de su empresa, fue precursor de los principios cooperativos de libre adhesión, retribución del capital con interés limitado, neutralidad política y religiosa y, sin duda, del principio de educación y formación.

En segundo lugar, y al igual que Owen, precursor indudable de la doctrina cooperativa se encuentra Charles Fourier (Besanzón, 1772). De origen francés e influido de manera notable por J.J. Rousseau la perspectiva de Fourier está en el origen de la doctrina cooperativa. A diferencia de Owen, la apuesta de Fourier no es tan industrial. Mientras Owen defendía el progreso para el hombre de la sociedad industrial (y criticaba la injusta redistribución de los beneficios), Fourier, seguramente por herencia de Rousseau, plantea que la sociedad industrial es precisamente la que ha fracturado a la sociedad en clases sociales.

De este modo, su planteamiento de una «comunidad» en forma de «falansterio» se mueve en el ámbito agrícola más que industrial. Su propuesta de vida en comunidad, heredera del planteamiento de los fisiócratas, gira en torno al cultivo de la tierra y los oficios derivados de esta: el falansterio es una unidad productiva autogestionaria de propiedad comunal. Observamos en la propuesta de Fourier un cierto alejamiento o retiro de la vida industrial (de la modernidad) y una vuelta al origen más artesanal y agrícola del hombre. Como decimos, influido por Rousseau y sus aires epicúreos, plantea que la sociedad industrial es la que ha producido las desigualdades sociales. Así, la forma de corregir dichas desigualdades se daría con una vuelta a una especie de hombre primitivo o salvaje y la condición de libertad asociada que Rousseau le asigna.

En esta línea de pensamiento rousseauniano se expresa Fourier en su obra Teoría de los cuatro movimientos publicada en 1808. En ella, distingue cuatro fases en el desarrollo de la humanidad (salvajismo, barbarie, patriarcado y civilización) siendo esta última la más desigua-

El precio de la materia prima no hacía rentable la producción, y la mayoría de las fábricas pararon y dejaron sin empleo a los trabajadores hasta que se solucionó la crisis, cuatro meses después. Pero Owen paró la producción sin dejar de pagar a los obreros, 7.000 libras en total sin más contrapartida que mantener la maquinaria limpia y en buenas condiciones. No se descontó ni un penique del salario de nadie». SANTOS, L.M., Robert Owen, pionero del management. [ Documentos de Trabajo de la Facultad de Ciencias Económicas y Empresariales; n. ${ }^{\circ} 27,2000$, ISSN: 2255-5471, pág. 13. 
litaria e injusta por las condiciones que genera para la mayoría de los hombres. La civilización produce, tanto en los hombres como en la propia sociedad, gran número de sinsabores y ridiculeces ${ }^{12}$. A pesar de su posición un tanto alejada de la sociedad industrial se pueden observar en Fourier los principios cooperativos de asociación voluntaria, democracia participativa, así como la neutralidad religiosa y política.

A partir de las posiciones de Owen y Fourier se abren dos perspectivas acerca del enfoque cooperativo: una, la que se construye a partir de los beneficios técnicos y productivos de la sociedad industrial, y otra, más conservadora, que plantea una vuelta a la organización en torno a la agricultura. En la tradición owenista situamos a los pioneros de Rochdale y a los defensores de la cooperativa industrial. Entre estos destaca la figura de Dionisio Aranzadi para quien «el cooperativismo debe adoptar una actitud positiva frente al avance técnico; la eficiencia de la producción debe ser un postulado básico () a su vez, debe asumir todos los avances sociales logrados por la reforma social»>13

Finalmente, entre los precursores de la doctrina cooperativa, aparece Claude-Henri de Rouvroy, Conde de Saint-Simon (Paris, 1970). A diferencia de Owen y Fourier, no encontramos en él una doctrina cerrada sino más bien una denuncia, de carácter teórico, de las condiciones de vida y trabajo que ha producido la revolución industrial. Su perspectiva se mueve en el terreno de la sociología descriptiva (recordemos que fue secretario de Auguste Comte) y se muestra especialmente crítico con las clases improductivas (clero, nobleza...) y siendo un firme defensor del trabajo de las clases populares para las cuales escribe un nuevo programa de vida y trabajo: El nuevo cristianismo (1825) en el que teoriza un nuevo modelo de vida basado en la fraternidad humana ${ }^{14}$.

12 FOURIER, Ch. Teoría de los cuatro movimientos y de los destinos generales, Ed. Barral, 1974, pág. 140.

13 ARANZADI, D., Cooperativismo industrial como sistema, empresa y experiencia, Universidad de Deusto, Bilbao, 1976, pág. 198.

14 «La nueva organización cristiana basará las instituciones temporales y espirituales en el mismo principio todos los hombres deberían tratarse entre sí como hermanos. Dirigiré todas las instituciones, sea cual sea su naturaleza, a incrementar el bienestar de la clase más pobre. Tengo, por tanto, una clara concepción de la nueva doctrina cristiana, y la desarrollaré. Voy a revisar todas las instituciones en Inglaterra, Francia, Alemania del norte y el sur, Italia, España, Rusia y América del Norte y del Sur. Compararé las doctrinas de estas instituciones con la doctrina dedicada directamente del principio fundamental de la moral divina, y convenceré fácilmente a todos los hombres de buena fe y buena voluntad que si todas estas instituciones estuvieran dirigidas a mejorar el bienestar moral y físico de la clase más pobre, proporcionarían con la mayor rapidez prosperidad a todas las clase de la sociedad y a todas las naciones». SAINT SIMON, H., El nuevo cristianismo, Ed. Biblos, Buenos Aires, 2004, p. 37. 
Sus discípulos más destacados también forman parte de la historia teórica del cooperativismo: el belga Philippe Buchez (Matagne-laPetite, 1796) fue pionero en Francia de las cooperativas de producción y el asociacionismo como solución a la situación de los trabajadores. Abogó, y su influencia es notoria en los principios cooperativos, por la distribución de beneficios dedicada a fines sociales o repartición entre socios y el principio de irrepartibilidad del capital social. Otro discípulo destacado de Saint-Simón fue Pierre-Joseph Proudhon (Besanzón, 1809). Su concepción sobre la remuneración del interés y la propiedad privada como robo son inspiradoras tanto del anarquismo como del cooperativismo. En último lugar, en España, encontramos a Louis Blanc (Madrid, 1811) que con su propuesta de los «talleres sociales» planteó que los beneficios laborales y sociales para los trabajadores se producirán si ellos son a la vez propietarios y trabajadores de los mismos.

Hasta este momento hemos explicado a los autores que han servido de inspiración general del movimiento cooperativo. En otras palabras, aquellos que han denunciado las condiciones de vida de la clase obrera producida por el liberalismo económico desde una perspectiva generalista. A continuación, vamos a exponer a los inspiradores teóricos de las ramificaciones prácticas o empresariales del cooperativismo, es decir, del cooperativismo con apellidos: cooperativismo de crédito o financiero, agrícola, de vivienda y escolar.

\section{Ramificaciones del ideal cooperativo}

\subsection{Cooperativismo financiero o de crédito}

Destacan en esta modalidad de cooperativismo dos autores principalmente: F.W. Raiffeisen (Sieg, 1818) y H. Schulze-Delitzsch (Delitzsch, 1808). Los elementos teóricos que inspiraron la propuesta de Raiffeisen los encontramos, sin duda, en la idea de Saint-Simón de lucha contra el «lucro» cuyo germen lo situamos en Luis de Molina. El origen de su posición es provocado como reacción a los efectos que la Revolución Industrial alemana produce en el campo y en la agricultura, desencadenados por las reformas legislativas de carácter liberal propuestas por K.F. von Stein y K.A. von Handerberg.

Estas reformas, provocaron que los campesinos, por primera vez, se convirtieran en gestores directos de sus propias tierras que pasaron a tener en propiedad, tarea para la que carecían de preparación específica; puesto que las tierras no fueron donadas sino vendidas, tuvieron que recurrir a la financiación. En este momento, se vieron obligados a 
entrar en contacto con los prestamistas que, aprovechándose del desconocimiento financiero de los campesinos, les impusieron intereses desmesurados; sumiéndoles en una profunda crisis económica ${ }^{15}$.

Como reacción a esta situación Raiffeisen, que fue alcalde de varias ciudades, propuso la creación de una entidad de apoyo financiero al mundo rural en 1847. Años más tarde, en 1864, creó la Asociación de Cajas de Préstamo de Heddesdorf. Los conceptos de caridad y fraternidad inspiraron el planteamiento de Raiffeisen dado que su concepción del crédito destilaba un fuerte carácter filantrópico. En la asociación creada en 1847 tuvo la intención de ayudar a los campesinos que estaban sufriendo las consecuencias de las malas cosechas producidas en Centroeuropa en 1846. El capital social de la asociación no estaba formado por las aportaciones de los socios (los propios campesinos estaban endeudados con los prestamistas), sino que provenía de agentes externos que, influidos por las mismas ideas de Raiffeisen, lo aportaban caritativamente para suavizar las condiciones a las que las reformas de Stein y Handenberg habían conducido a los propietarios de las tierras.

La aportación de capital externo no resolvía los problemas pues, en el fondo, era fruto de la filantropía y no de la productividad de la actividad empresarial. Raiffeisen era consciente de esta situación y al fundar la Asociación de Cajas de Préstamo, introdujo la obligación de aportación al capital social por parte de los asociados (campesinos). También estableció que los beneficios generados por la actividad económica no debían ser repartidos, sino destinados a un fondo de garantía de reserva o a la acción social. A partir de aquí, Raiffeisen establece la existencia del fondo de reserva obligatorio y del fondo de garantía; elementos básicos en cualquier sociedad cooperativa, como elementos no repartibles.

Contemporáneo a Raiffeisen, establece su pensamiento el economista alemán Franz Hermann Schulze-Delitzsch (Delitzsch en 1808). A diferencia de Raiffeisen y su marcado carácter religioso, Schulze se mueve en el terreno económico y político de la izquierda política. Su perspectiva no se restringe al ámbito del campesinado, sino que tiene

15 «Los bancos no se interesan por una clientela de pequeños agricultores. Estos solo podían dirigirse a los propietarios si eran arrendatarios o aparceros; a los comerciantes que les vendían provisiones o compraban sus productos; o a prestamistas especializados. Todos tendían a abusar de su situación dominante exigiendo intereses exorbitantes (...) En el sudeste de Asia los campesinos incluso llegaban a ser a menudo esclavos por deudas. La primera necesidad de una clase rural pobre es, pues, quedar libre de la usura». LASSERRE, G., El cooperativismo, op. cit. págs. 84-85. 
una dimensión general: artesanos, pequeños industriales, profesiones liberales Defiende que el funcionamiento del crédito y sus beneficios gestionados adecuadamente, es decir, revirtiéndose en la propia sociedad que los genera, eliminarían la miseria y la pobreza.

Bajo los principios generales de ayuda mutua y ahorro obligatorio, se formaría el capital social de la sociedad y este se convertiría, a su vez, en la base económico-financiera. El capital externo no tenía lugar en tanto que debían ser los propios socios los que generasen los recursos económico-financieros. La empresa debía ser muy exigente con el ahorro por parte de los socios pues, como decimos, es la base de la sociedad y entre otras medidas, se estableció la penalización por el retraso en los pagos (como ya estableciesen también los pioneros de Rochdale).

La obra de Schulze plantea una concepción de la cooperativa de crédito con un marcado carácter social y económico alejada de los principios filantrópicos y caritativos propuestos por Raiffeisen. Las cooperativas de crédito ideadas por Schulze poseen grandes similitudes con las sociedades mercantiles en cuanto a liquidez y rentabilidad. Sin embargo, su intención era la de ser una alternativa al crédito del mercado capitalista y su componente lucrativo.

\subsection{Cooperativismo de vivienda}

Aunque no existe una figura o nombre concreto de esta modalidad cooperativa, podríamos situar como precedentes teóricos de las cooperativas de viviendas a las "aldeas cooperativas» de Owen y el falansterio de Fourier. La doctrina general cooperativa establece que la actividad productiva debe ser útil para satisfacer todas las necesidades humanas y no solo las empresariales o productivas.

La vivienda sería una de ellas y probablemente fue en torno a la experiencia de Rochdale cuando apareció como forma más o menos definida el planteamiento. De nuevo, la idea surge como reacción a las condiciones de arrendamiento de las viviendas de los Pioneros. El propietario de esas viviendas decidió subir el alquiler siendo este de difícil acceso para los trabajadores. Esta situación problemática fue la que les llevó a desarrollar de forma práctica el artículo I de sus Estatutos y configurar una sociedad (empresa) para adquirir terrero y construir viviendas para los socios. En 1867 construyeron 37 casas en mejores condiciones y con más prestaciones que las anteriormente alquiladas, con la idea última, según apunta Antonio Gascón y Miramón, de construir una pequeña ciudad cooperativa. 
A pesar de no tener un desarrollo desatacado durante el siglo XIX y gran parte del xx de esta forma de cooperación asociada a la vivienda, actualmente, es una forma muy extendida; en Francia, España, Dinamarca e incluso EE. UU. las personas recurren al asociacionismo cooperativo para la compra de viviendas (siendo Suecia el país más desarrollado en esta modalidad empresarial). Aproximadamente, al 23\% de la población reside en domicilios que han sido construidos bajo el régimen cooperativo. La Cooperativa de Vivienda y Hábitat (HSB en sueco) fundada en 1923 es, en la actualidad, una de las cuatro grandes corporaciones suecas en gestión de vivienda. La forman 600.000 cooperativistas asociados y poseen más de 300.000 viviendas en más de 1.200 promociones por todo el país.

\subsection{Cooperativismo agrícola}

En el caso del crédito agrícola surge como modelo de financiación de la actividad en su nueva etapa de autogestión por parte de los campesinos. Esta situación que dio lugar al pensamiento de Raiffeisen-Schulze introdujo notables mejoras en las condiciones de desarrollo de la actividad ${ }^{16}$. El modelo Raiffeisen-Schulze propició la creación de Cajas Rurales (Cajas-Raiffeisen) cuya misión era la financiación, en principio a coste cero (recordemos que se sitúan frente al prestamismo de carácter usurero), de la actividad autogestionaria de los campesinos.

El modelo de Cajas Rurales se extendió rápidamente dando como resultado diferentes modelos de financiación en diversos países. El inspirador último del cooperativismo agrícola es el propio Raiffeisen pues, aun-

16 ¿Por qué fue tan difícil expandir una oferta de servicios financieros rurales? Todos los informes oficiales que se realizaron en este período mostraban su preocupación por la falta de acceso de los agricultores a los servicios financieros formales y por los duros términos y condiciones (en particular, las elevadas tasas de interés) de las finanzas informales. El diagnóstico de esta situación incorporaba dos elementos centrales: - Los banqueros eran demasiado conservadores, no estaban interesados en el crédito agrícola o en prestar a agricultores pobres. - La usura ejercida por los prestamistas informales a través de las exorbitantes tasas de interés que cobraban eran una forma de explotación. Estas dos explicaciones aparentemente distintas tenían un elemento común: la voluntad. Los problemas de las finanzas rurales se atribuían a la ausencia de ésta (indiferencia) en los banqueros comerciales privados y a la mala voluntad (intención de explotación) de los prestamistas informales. Los banqueros no querían atender a este tipo de clientela; los prestamistas buscaban explotarla», MARTíNEZ-SOTO, A.P., «Los orígenes del cooperativismo de crédito agrario en España, 1890-1934), Revista CIRIEC-España de Economía Pú-

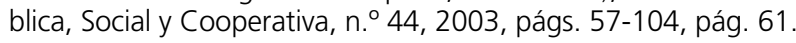


que su preocupación fue el crédito, dio lugar a la consideración por parte del campesinado de las ventajas de la asociación y la ayuda mutua17.

Los principios reguladores de la activad cooperativa agrícola se establecieron en el Congreso Internacional Raiffeiseniano celebrado en Tarbes (Francia) en 1867. Dichos principios abogaban por un uso debido del crédito, responsabilidad de los socios, ahorro, cargos no remunerados, solvencia y honradez de los socios ${ }^{18}$. Estos principios básicos proyectaban la actividad del crédito agrario que fue la causa del nacimiento del asociacionismo rural cooperativo. Este modelo se extendió rápidamente por Dinamarca desde que en Thisted (1886) se fundó la primera cooperativa de consumidores. Actualmente Dinamarca es un modelo en la producción y consumo de actividad cooperativa agraria, en concreto en el ámbito de la leche y la carne de cerdo llegando a alcanzar el $90 \%$ de la producción, el 30\% de las exportaciones y siendo el sector con mayor tasa de empleabilidad en el país ${ }^{19}$.

\subsection{Cooperativismo escolar}

De igual modo que en las anteriores manifestaciones del movimiento cooperativo, el cooperativismo educativo o escolar tiene también sus orígenes en los precursores (Owen, Fourier, Saint-Simón) así

17 «Raiffeisen podría ser considerado como el padre de las cooperativas agrícolas porque fue el primero que ideó la liberación y el progreso del agricultor por medio de las cooperativas [...], el único medio de liberar a los agricultores era darles dinero a bajo costo. Es lo que hizo Raiffeisen con sus Cajas. Los agricultores aprendieron además a ahorrar y asociarse, los dos fundamentos de la cooperación agrícola», GARCÍA MUÑOZ, Q., Cooperativismo y desarrollo, Ed. Marsiega, Madrid, 1973, págs. 141-142

18 1. El fin es procurar a los socios (agricultores) provecho material y moral por el crédito, aplicado preferentemente a las necesidades de la empresa agrícola y de la familia campesina. 2. La actividad de la Caja se extiende a un municipio, parroquia o una circunscripción pequeña equivalente. 3. Los cargos de la administración se desempeñan, por regla general, gratuitamente. 4. Los socios son responsables de las operaciones de la Caja solidaria e ilimitadamente. 5. La Caja no presta sino a sus socios, teniendo en cuenta su honradez y solvencia. 6. Los socios no perciben dividendos y los beneficios que realiza la Caja forman una reservar que no puede repartirse entre aquellos, ni aún en caso de disolución Principios» ARCO ÁLVARES, J.L. del, «El crédito agrícola cooperativo y el informe del Banco Mundial», Revesco Estudios Cooperativos, n. ${ }^{\circ} 13,1967$, págs. 53-65.

19 "Las empresas cooperativas se han exigido ser las más fuertes en los dos sectores más orientados a la exportación, cerdos y leche, donde casi el 100\% del sector es propiedad de las cooperativas. En el ramo de la ganadería cerca de dos terceras partes del sector es manejado por cooperativas. Las cooperativas también tienen una importante participación en los subsectores de pieles y granos. En el sector de insumos para granja, aproximadamente el $50 \%$ de la producción está a cargo de las cooperativas», http://confecoop.coop/cooperativismo/en-el-mundo/dinamarca/ 
como en la formulación de los Principios y Fines de Rochdale. Desde Rochdale hasta la Declaración de la ACI en 1995, el papel de la educación resulta esencial a la doctrina desde el artículo primero de los Estatutos de Rochdale hasta el quinto de la Declaración de Manchester ${ }^{20}$.

Tanto Owen como Fourier o Saint-Simon inspiran sus reflexiones empresariales y antropológicas en torno al concepto de educación natural que se encuentra en Rousseau. Cierto es que la influencia es mucho más notoria en Fourier, quizá porque en Francia la influencia del pensador ginebrino fue mayor que en Inglaterra. En cualquier caso, los precursores de la doctrina cooperativa establecen que una de las claves del éxito de la empresa cooperativa se encuentra en la educación y formación de los socios. Sin embargo, no restringen la educación al ámbito de la formación empresarial como un deber estatutario, sino que consideran que los principio y valores cooperativos formen parte del programa educativo escolar.

En esta línea, José María de Arizmendiarrieta, fundador de la Cooperativa Mondragón, afirmaba que antes de establecer cooperativas era necesario contar con cooperativistas y que lo contrario supondría un peligro para la subsistencia del modelo empresarial cooperativo ${ }^{21}$, dando relevancia a la formación ideológica y «filosófica» cooperativista como elemento imprescindible para el buen curso del modelo empresarial. En esta línea destacan históricamente dos autores: Barthélemy Profit (Lonzac, 1847) y Célestin Freinet (Gars, 1896).

20 En las sucesivas Declaraciones de Principios cooperativos se ha mantenido el Principio de Educación y Formación. Así, en Rochdale, 1844, se establecía el «principio de educación continua», en la Declaración de París, 1937, «principio de fomento de la enseñanza», en la Declaración de Viena, 1966, "Fomento de la educación» y en la actual declaración de Manchester, 1995, «Educación, Formación e Información». Así, se determina la importancia capital de la cuestión educativa en el desarrollo del movimiento cooperativo: "Para el caso del cooperativismo la formación adquiere una connotación especial, pues constituye, además, un proceso concreto dirigido a formar valores y principios, conducentes a la verdadera cooperación entre todos los miembros de la cooperativa, que permita lograr el sentido de pertenencia, identidad, motivación e implicación en el desarrollo socioeconómico de la organización que coadyuven al desarrollo del sector», MARÍN, I., LABRADOR, O. Y MIRABAL, Y., "La educación cooperativa como eje central para la formación integral en el sector cooperativo», Cooperativismo y Desarrollo, Vol. 1, Cuba, 2013, págs. 70-85, pág. 75.

21 «Naturalmente necesitamos que antes que cooperativas haya cooperativistas. $Y$ no pueden ser cooperativistas, no deben clasificarse entre tales, los que hacen de la propia capacidad un recurso para exclusivo servicio propio, que sean incapaces de una elevación de miras. No deben enrolarse en las cooperativas quienes no conciben la propia promoción individual solidariamente con la promoción colectiva. El cooperativista necesita conjugar el sentido de dignidad y miras propias con las exigencias de la comunidad, y a este respecto es necesario que acepte una jerarquía, un orden, una previsión y hasta unas deficiencias ajenas». AZURMENDI, J., El hombre cooperativo. Pensamiento de Arizmendiarrieta, Ed. Azazta, Otalora, 2001, pág. 507. 
B. Profit fundó en 1919 una cooperativa escolar (Les petites AbeiIles) cuya finalidad fue reunir fondos para solventar las necesidades más urgentes de la escuela, entre ellas, la adquisición de material escolar. Su propuesta aparece como intento de solución a los problemas de financiación para construir una escuela una vez finalizada la Primera Guerra Mundial. Profit plantea una nueva forma de financiación de la actividad escolar así como una renovación de la metodología educativa a partir del concepto de ayuda mutua. El aprendizaje y el sustento económico de la actividad educativa debía estar basado en la cooperación por parte de la comunidad educativa. La instrucción técnica (la formación propiamente académica) debía estar complementada con los principios éticos derivados de la ayuda mutua.

Profit entiende que la escuela debe estar organizada según los principios del cooperativismo. La escuela debe ser un garante de la educación moral, cívica y social de los ciudadanos basada en los principios del bien común y la ayuda mutua. A su vez, la actividad educativa debe estar alejada y mostrarse crítica con las ideologías políticas implantadas, es decir, materializando en la rama del cooperativismo escolar el principio de «neutralidad e independencia» de los principios cooperativos. Además, pueden observarse en la concepción escolar de Profit el principio de asociación libre y fraternal que establece en el primer principio cooperativo.

Célestin Freinet se sitúa en la misma línea que Profit, con la peculiaridad de que su proyecto de escuela cooperativa se enfoca desde la perspectiva política comunista. Su preocupación social le llevó a fundar en Gars, su pueblo natal, una cooperativa de trabajadores para solucionar la falta de electricidad. En 1934 se inicia en Vence con apoyo de Partido Comunista, la Escuela de Enseñanza Laica a la que acuden alumnos de las clases populares. Una vez terminada la II Guerra Mundial, donde Freinet pasó por un campo de concentración, la Escuela de Enseñanza Laica se convirtió en el Instituto de la Escuela Moderna, cuya misión, aparte de la escolar, fue la edición y difusión de material escolar con las aportaciones de la «nueva pedagogía» cooperativa y comunista creada por Freinet: producción del texto libre, imprenta escolar, trabajo cooperativo, organización asamblearia, biblioteca de trabajo. eran los elementos de la nueva metodología escolar que, influida por el ideal comunista, cambiaría el mundo22.

22 Ver al respecto, JIMÉNEZ, R., «El modelo didáctico de las técnicas Freinet: una síntesis práctica de los principios básicos contemporáneos», Revista de educación Tavira, Universidad de Cádiz, 1987, n. 4, págs. 85-110. Para un análisis más completo ver PIATON, G., El pensamiento pedagógico de Celestino Freinet, Ed. Marsiega, Madrid, 1975. 
El movimiento escolar cooperativo iniciado en Francia por Profit y Freinet tuvo rápida difusión y propició la creación de escuelas cooperativas. En 1928 se crea en Francia la Office Central de la Coopération a l'Ecole, que coordina el movimiento cooperativo y la articulación de una estructura normativa común, en 1964 se crea la Comisión Internacional de Cooperación Escolar vinculada a la Organización Internacional del Trabajo que llega hasta nuestros días denominándose desde el año 1984, Alianza Internacional para la Cooperación entre Escuelas (IACS) donde actualmente tiene presencia en 67 del mundo 23 .

\section{Marxismo, cooperativismo y catolicismo: Gide, Pfeiffer, Staudinger}

La segunda mitad del siglo XIX es especialmente interesante desde el punto de vista teórico por la confluencia en el mismo de la doctrina cooperativa con el marxismo y el catolicismo. Bien es cierto que la doctrina católica había inspirado a los precursores de la doctrina tanto en su crítica a la usura como en su defensa de los bienes comunes, pero la aparición del socialismo marxista supuso la necesidad de resituar los principios y las prácticas cooperativistas.

En este sentido, es innegable, tal y como ha demostrado Eba Gaminde la influencia en la doctrina cooperativa de la doctrina social de la Iglesia ${ }^{24}$. Ahora bien, no es menos cierto que la doctrina marxista y su fuerte aparición desde, al menos, la publicación del Manifiesto Comunista en 1848 han sido determinantes en el desarrollo teórico y práctico del cooperativismo. En esta línea, algunos autores, plantean una cierta identidad entre el planteamiento cooperativo y el del socialismo marxista. Quizá, el ejemplo paradigmático de este posición lo encontra-

${ }^{23}$ Ver al respecto, INGLADA, M.E. y otros, «El cooperativismo en la educación», Revesco Estudios Cooperativos, Universidad Complutense de Madrid, n. ${ }^{\circ}$ 118, 201, págs. 122-147.

24 «Se puede decir que la solidaridad cooperativa procede de la piedad religiosa, que se mantiene en el tiempo como una de las líneas doctrinales cooperativas constante en el tiempo. La idea de ayuda mutua, de preocupación por el prójimo que subyace de forma más o menos acentuada y con diferentes matices en todo este proceso evolutivo hace que frecuentemente se vincule el cooperativismo con el denominado cristianismo social», GAMINDE, E., La doctrina social cristiana y el cooperativismo vasco; una alternativa para el cambio, Ed. Dykinson, Madrid, 2017, pág. 55. 
mos en Geroges Lasserre, profesor de Derecho y Economía en París en los años $70^{25}$.

De este modo, la aparición del marxismo va a producir un movimiento de posiciones de la doctrina cooperativa y de la doctrina católica, de tal forma que desde la perspectiva católica se va a reclamar su vinculación con el cooperativismo alejada del marxismo. De hecho, Pio XI en su Encíclica Quadragesimo anno (1931) llega a afirmar que nadie puede ser a la vez buen católico y verdadero socialista 26.

Las diferentes teorías acerca del cooperativismo como herramienta de transformación social y la toma de posiciones con respecto al mundo obrero, sobre todo en la Encíclica Rerum Novarum de León XIII (1891), van a producir un escenario teórico muy interesante. Así, las perspectivas de Charles Gide (Uzés, 1847) y de Eduard Pfeiffer (Stuttgart, 1835) se situarán de forma clara frente al incipiente socialismo marxista.

Charles Gide pertenece a la Escuela de Nimes y es considerado el fundador del cooperativismo de consumo en Francia. Economista de formación, liberal y católico, propuso el concepto de «República cooperativa» como solución equidistante del incipiente socialismo de raigambre marxista y del capitalismo. Su pensamiento se sitúa en los principios de la economía participativa y autogestionaria cuya base teológica se encuentra, como hemos señalado, en la Rerum Novarum (1891). Su finalidad última es acercar al movimiento obrero (y por tanto cooperativo) a la Doctrina Social de la Iglesia y, a la vez, alejarlo del socialismo marxista27.

25 «Las nacionalizaciones responden al mismo fin del cooperativismo: sustraer a las empresas de ley capitalista de la búsqueda de mayor beneficio posible, considerada particularmente intolerable en cierto número de industrias clave; y crear empresas de servicio funcionando en vistas al interés general». LASSERRE, G., El cooperativismo, op. cit., pág. 55.

26 «El socialismo es un sistema que priva al individuo de su propiedad para enriquecer a la sociedad, lo que en definitiva supone un perjuicio para ambos, individuo y sociedad () el Señor pretender liberar las almas y los corazones de los bienes terrenales para aspirar a bienes eternos y supremos en una vida futura, mientras que los comunistas, por el contrario, proponen como único objetivo, precisamente, la consecución de estos bienes terrenales», GAMINDE, E., La doctrina social cristiana y el cooperativismo vasco: una alternativa para el cambio, op. cit., pág. 200.

27 «Y éstos, los deberes de los ricos y patronos: no considerar a los obreros como esclavos; respetar en ellos, como es justo, la dignidad de la persona, sobre todo ennoblecida por lo que se llama el carácter cristiano. Que los trabajos remunerados, si se atiende a la naturaleza y a la filosofía cristiana, no son vergonzosos para el hombre, sino de mucha honra, en cuanto dan honesta posibilidad de ganarse la vida. Que lo realmente vergonzoso e inhumano es abusar de los hombres como de cosas de lucro y no estimarlos en más que cuanto sus nervios y músculos pueden dar de sí. E igualmente se manda que se tengan en cuenta las exigencias de la religión y los bienes de las almas de 
El propio Gide destaca, no por casualidad, el papel que tiene el «amor» (caridad) como base última sobre la que deba fundarse cualquier acción o política humana ${ }^{28}$. Esta tesis se posiciona claramente a favor de la doctrina católica, frente al socialismo ateo y revolucionario que plantea la quiebra del sistema por medios violentos ${ }^{29}$.

los proletarios. Por lo cual es obligación de los patronos disponer que el obrero tenga un espacio de tiempo idóneo para atender a la piedad, no exponer al hombre a los halagos de la corrupción y a las ocasiones de pecar y no apartarlo en modo alguno de sus atenciones domésticas y de la afición al ahorro. Tampoco debe imponérseles más trabajo del que puedan soportar sus fuerzas, ni de una clase que no esté conforme con su edad y su sexo. Pero entre los primordiales deberes de los patronos se destaca el de dar a cada uno lo que sea justo [...] la riqueza nacional proviene no de otra cosa que del trabajo de los obreros. La equidad exige, por consiguiente, que las autoridades públicas prodiguen sus cuidados al proletario para que éste reciba algo de lo que aporta al bien común, como la casa, el vestido y el poder sobrellevar la vida con mayor facilidad. De donde se desprende que se habrán de fomentar todas aquellas cosas que de cualquier modo resulten favorables para los obreros. Cuidado que dista mucho de perjudicar a nadie, antes bien aprovechará a todos, ya que interesa mucho al Estado que no vivan en la miseria aquellos de quienes provienen unos bienes tan necesarios». LEÓN XII, Rerum Novarum, 1891.

28 Esta línea inaugurada con León XII volvió a aparecer precisamente en la Encíclica «Deus caritas est» de Benedicto XVI el 25 de diciembre de 2015: "Desde el siglo XIX se ha planteado una objeción contra la actividad caritativa de la Iglesia, desarrollada después con insistencia sobre todo por el pensamiento marxista. Los pobres, se dice, no necesitan obras de caridad, sino de justicia. Las obras de caridad - la limosna - serían en realidad un modo para que los ricos eludan la instauración de la justicia y acallen su conciencia, conservando su propia posición social y despojando a los pobres de sus derechos. En vez de contribuir con obras aisladas de caridad a mantener las condiciones existentes, haría falta crear un orden justo, en el que todos reciban su parte de los bienes del mundo y, por lo tanto, no necesiten ya las obras de caridad. Se debe reconocer que en esta argumentación hay algo de verdad, pero también bastantes errores. Es cierto que una norma fundamental del Estado debe ser perseguir la justicia y que el objetivo de un orden social justo es garantizar a cada uno, respetando el principio de subsidiaridad, su parte de los bienes comunes. Eso es lo que ha subrayado también la doctrina cristiana sobre el Estado y la doctrina social de la Iglesia. La cuestión del orden justo de la colectividad, desde un punto de vista histórico, ha entrado en una nueva fase con la formación de la sociedad industrial en el siglo XIX. El surgir de la industria moderna ha desbaratado las viejas estructuras sociales $y$, con la masa de los asalariados, ha provocado un cambio radical en la configuración de la sociedad, en la cual la relación entre el capital y el trabajo se ha convertido en la cuestión decisiva, una cuestión que, en estos términos, era desconocida hasta entonces. Desde ese momento, los medios de producción y el capital eran el nuevo poder que, estando en manos de pocos, comportaba para las masas obreras una privación de derechos contra la cual había que rebelarse».

29 «Ni Gide ni la Escuela de Nimes han defendido nunca la revolución, en el sentido de un cambio violento, por la fuerza, de la organización económica y social existente. Pacifista convencido, Gide rechaza de una manera tajante la violencia y confía llegar al nuevo orden económico mediante solo el empleo de medios de esta naturaleza. No es- 
El planteamiento de Gide establecía un plan de implantación de la República Cooperativa que fue presentado en el IV Congreso Cooperativo celebrado en París en 1899, bajo el título «Plan de las tres Etapas». En la primera, se establecería la agrupación de sociedades y la utilización de sus beneficios para crear almacenes al por mayor y compras a gran escala. En la segunda etapa, se adquirirían fábricas e industrias para cubrir las necedades de los socios y, por último, la tercera fase sería de adquisición de tierras para la producción directa de las materias primas que nutran a las fábricas para finalizar el proceso autogestionario. Dicho "en pocas palabras, en una primera etapa victoriosa, conquistar la industria comercial; en una segunda, la industria manufacturera; por último, en una tercera, la industria agrícola, este deber ser el programa de la Cooperación» ${ }^{30}$.

En Alemania encontramos al fundador de la Escuela de Hamburgo, Eduard Pfeiffer, que en la misma línea que Gide, abogó por las cooperativas de consumo como elemento de transformación gradual hacia una sociedad más justa. Trató de propagar entre la clase obrera el distanciamiento de la doctrina marxista pues entendía que el paso hacia la sociedad cooperativa debía ser pacífico y paulatino, no revolucionario ni violento. Aunque preservaba, como Gide, la idea de transformación social, fundó junto a otros amigos el Partido Nacional Liberal y se convirtió en el primer ciudadano de origen judío con escaño en el parlamento de Württemberg. En 1866 fundó la Asociación para el bienestar de las clases trabajadoras.

Entendió que el cooperativismo debía cubrir no solo las necesidades productivas, sino todos los aspectos de la vida; se ocupó de la mejora de los servicios sanitarios, la construcción de un hospital infantil, bibliotecas, servicios públicos, establecimientos de venta de alimentos de primera necesidad y la creación de aproximadamente 1800 viviendas des-

peramos — decía- de la intervención del Estado ni de un poder coercitivo cualquiera la realización del orden social que acabo de describiros (se refería al programa de las tres etapas), sino solamente de la libre iniciativa individual ejerciéndose mediante la asociación voluntaria y obrando siempre conforme al derecho común. En una de sus conferencias advertía: "aquellos que os dicen que el orden económico existente puede ser cambiado por un golpe de mano, se equivocan y hacen equivocar a los demás. Si se tratara de una revolución política, es posible. Tres días pueden ser suficientes para destronar a un rey — inada más frágil que un trono! - pero cuando se trata de reemplazar el organismo económico entero por un organismo nuevo, es necesario un trabajo de larga elaboración anticipada». OROZCO, J., Antología doctrina cooperativa, Ed. Universidad Estatal a Distancia, San José de Costa Rica, 1986, págs. 177-178.

30 OROZCO, J., Antología doctrina cooperativa, Ed. Universidad Estatal a Distancia, San José de Costa Rica, 1986, pág. 176. 
tinadas a los obreros ${ }^{31}$. Participó en la creación de escuelas infantiles, en las que veía un elemento básico en la formación de las ideas asociacionistas y cooperativistas.

Las ideas de Pfeiffer, al igual Gide, dieron lugar a la denominada Escuela de Hamburgo cuando después del Congreso de Kreuznach (1902) se creó la Unión Central de Cooperativas de Consumo. En la Escuela, destacó la labor teórica Franz Staudinger, quien se alejó del planteamiento con base cristiana, probablemente influido por la obra de Kant, para acercarse al marxismo, donde encontraba un planteamiento con una base material más firme que el de la doctrina católica denominándose «socialismo cooperativo» 32.

De este modo, podemos observar cómo el marxismo ha provocado movimientos de posiciones (reafirmación, alejamiento, alineamiento ) en los autores de mediados del siglo XIX y principios del XX. El marxismo, al menos en sus figuras originarias Marx y Lenin, ha tenido una posición un tanto peculiar sobre el cooperativismo. Dicha concepción, influida por su idea final de instauración de una sociedad sin clases y sin religión, veía en el cooperativismo un posible compañero de viaje del que separarse al llegar al final del camino. El cooperativismo es visto por Marx a través de la opinión que este profesaba sobre los precursores ideológicos, denominados por Engels socialistas utópicos. Owen o Fourier, para Engels, aciertan en su diagnóstico de la sociedad capitalista, pero no desde una óptica histórica materialista, sino más bien inspirados por una suerte de cristianismo fraternal. Dicha influencia mística les impediría proporcionar un diagnóstico verdaderamente revolucionario de transformación social hacia el comunismo, resultando su propuesta utópica, ingenua y no realizable. Sin embargo, a diferencia de Engels, Marx tenía una visión positiva de las cooperativas, tal y como expresa en El Capital, pues veía

31 «Esta iniciativa le sirvió para ser nombrado ciudadano de honor de la ciudad de Stuttgart en 1909. Durante los años del nacionalsocialismo desapareció del ámbito público. Pfeiffer murió el 13 de mayo y antes de fallecer creo la Fundación Pfeiffer con su riqueza acumulada», CASADO, I., Diccionario de Economía Social, Ed. Ecoobook, Madrid, 2009, pág. 243.

32 «Cuando, después del Congreso de Kreuznach (1902) se constituyó la Unión Central de Cooperativas Alemanas de Consumo, que fijó su sede en Hamburgo, bajo la influencia de las ideas de Pfeiffer, se desarrolla paralelamente a la Escuela de Nimes en Francia, una escuela cooperativista llamada «tendencia de Hamburgo», se hizo célebre gracias al profesor Franz Staudinger, cuyas principales publicaciones datan de 1908, 1914 y 19119; para él, el consumidor distribuye rentas, crea el capital y debe detentar la totalidad del poder económico». LAMBERT, P., La doctrina cooperativa, op. cit., pág. 115. 
en ellas el primer momento de la historia donde los trabajadores eran dueños de los medios de producción ${ }^{33}$.

En el caso de Lenin, que sigue la línea teórica de Marx y Engels, las cooperativas son una herramienta útil para la consecución del socialismo. Según Lenin, las cooperativas aúnan todas las virtudes del socialismo y deben ser utilizadas como medios adecuados para alcanzar la sociedad futura: los socialistas cultos son cooperativistas decía Lenin ${ }^{34}$. Sin embargo, aun reconociendo el carácter social de las cooperativas, el desarrollo del socialismo real ha determinado que las cooperativas son herramientas de la producción sometida a la economía planificada. En ellas, el principio de autonomía e independencia, básico en la doctrina cooperativa, no fue considerado. En este sentido, el cooperativismo bajo el socialismo ha tenido un carácter instrumental al servicio de la economía planificada ${ }^{35}$.

33 "Las fábricas cooperativas de los obreros mismos son, dentro de la forma tradicional, la primera brecha abierta en ella, a pesar de que, donde quiera que existan, su organización efectiva presenta, naturalmente y no puede menos que presentar, todos los defectos del sistema existente. Pero dentro de estas fábricas aparece abolido el antagonismo entre el capital y el trabajo, aunque, por el momento, solamente bajo una forma en que los obreros asociados son sus propios capitalistas, es decir, emplean los medios de producción para valorizar su propio trabajo. Estas fábricas demuestran cómo al llegar a una determinada fase de desarrollo de las fuerzas materiales producidas y de las formas sociales de producción adecuadas a ellas, del seno de un régimen de producción surge y se desarrolla naturalmente otro nuevo. Sin el sistema fabril derivado del régimen capitalista de producción no se hubieran podido desarrollar las fábricas cooperativas, y mucho menos sin el sistema de crédito, fruto del mismo régimen de producción. El sistema de crédito, base fundamental para la gradual transformación de las empresas privadas capitalistas en sociedades anónimas capitalistas, constituye también el medio para la extensión paulatina de las empresas cooperativas en una escala más o menos nacional. Las empresas capitalistas por acciones deben ser consideradas al igual que las fábricas cooperativas, como formas de transición entre el régimen capitalista de producción y el de producción asociadas; la única diferencia es que en un caso el antagonismo aparece abolido negativamente, mientras que en el otro aparece abolido en sentido positivo». MARX, K., El Capital, Tomo III, F.C.E., México, 1968, pág. 418.

34 «[ ] La segunda de nuestras tareas consiste en nuestra labor cultural [que] persigue precisamente como objetivo económico, la organización de cooperativas. Si pudiéramos organizar en cooperativas a toda la población, ya estaríamos con ambos pies en suelo socialista, pues cuando los medios de producción pertenecen a la sociedad, cuando es un hecho el triunfo de la clase del proletariado sobre la burguesía, el régimen de los cooperadores cultos es el socialismo». LENIN, V.I., "Sobre la cooperación», Tareas de las juventudes comunistas», Obras Escogidas en 12 vol., Tomo 3, Editorial Progreso, Moscú, 1961, pág. 781

35 «El Estado fue consiguiendo rápidamente un predominio efectivo; $y$, una vez que su red comercial, y sobre todo la cooperativa, fue realmente extendida a las zonas rurales, puedo eliminar al comercio privado vedándole de artículos manufacturados, y a la industria privada imposibilitándole de combustible y materias primas, en la forma y 
Sin embargo, la aparición del marxismo y el socialismo real obligó a la doctrina cooperativa a situarse como un elemento productivo que opera bajo cualquier régimen económico. Tanto en el capitalismo como en el socialismo, el cooperativismo existió de forma ininterrumpida desde Rochdale. Como es natural, el desarrollo de este movimiento se establece en permanente dialéctica con la realidad histórica y política en la que se desenvuelve. El resultado de esta situación es la evolución de los principios cooperativos que, como elementos reguladores de la actividad empresarial, se han ido transformado, adaptando y redefiniéndose ${ }^{36}$.

\section{Rochdale y los principios cooperativos: breve recorrido hasta nuestros días}

En Rochdale, 1844, se forma la primera cooperativa que alberga en sus estatutos el establecimiento de unos principios cooperativos. Son los primeros de la historia del movimiento y, por su estructura, serán fuente constante de inspiración del movimiento ${ }^{37}$. Los Estatutos de Rochdale reflejan la primacía e importancia del trabajo frente al capital en cuanto a la redistribución de los beneficios y la articulación del entramado de gestión de la empresa.

Los principios de Rochdale fueron discutidos y en algunos casos reformulados o reconstruidos por las sucesivas propuestas de la Alianza Cooperativa Internacional. Las diferentes formulaciones representan el origen de los valores y principios que rigen a los grupos humanos que se organizan empresarialmente bajo la fórmula cooperativa.

En 1895 se funda en Londres la Alianza Cooperativa Internacional $(\mathrm{ACl})$ con el objetivo de reunir los diversos modos de actividad coope-

momento que se juzgaron oportunos. De hecho, el comercio minorista de las cooperativas, fomentado y sostenido por el Estado, se multiplicó con suma rapidez. En 1922-23 su participación en el volumen total de las ventas al por menor era solo del 10\% (frente al 75\% del comercio privado); en 1926-27 su cifra de ventas se había multiplicado por 19», NOVE, A., Historia Económica de la Unión Soviética, Ed. Alianza, Madrid, 1973, págs. 109-100.

36 Observemos brevemente esta evolución desde Rochdale hasta nuestros días con los principios de Manchester del año 1995 y la Declaración de Identidad Cooperativa. Un breve resumen muy ilustrativo se encuentra en MARTINEZ CHARTERINA, A., La COOperativa y su identidad, Ed. Dykinson, Madrid, 2016, págs. 45-54.

37 1. Libre adhesión, 2. Control democrático, 3. Devolución o bonificación sobre las compras, 4. Interés limitado al capital, 5. Neutralidad política y religiosa, 6. Ventas al contado, 7. Fomento de la enseñanza. 
rativa que se habían ido produciendo a lo largo del siglo XIX. A pesar de sus reuniones periódicas, será en el XV Congreso celebrado en París en 1937 donde se formularon los principios cooperativos, poniendo de manifiesto que los de Rochdale podían no dar respuesta a los problemas que aparecieron años después ${ }^{38}$. Así, en 1937 se establecen las características de una sociedad cooperativa: libre adhesión, control democrático, distribución a los socios del excedente a prorrata de sus compras y el interés limitado del capital. Como principios de carácter secundario, y por lo tanto no necesarios para pertenecer a la $\mathrm{ACl}$, se establecía la neutralidad política y religiosa, la venta al contado y el desarrollo de la educación.

El establecimiento de cuatro principios para pertenecer a la $\mathrm{ACl}$ estaba condicionado por la necesidad de reclutamiento del mayor número de sociedad posibles y el intento de configurar un movimiento fuerte. Para ello, no cabía la posibilidad de mostrarse excesivamente exigente $y$, por ello, se establecieron cuatro principios básicos; el resto tenía un carácter voluntario. En el Congreso de Viena (1966) desaparece el principio de neutralidad política y religiosa con el objetivo de poder incluir como miembros de derecho de la $\mathrm{ACl}$ a las cooperativas existentes en los países comunistas cuya organización dependía, en última instancia, del Estado. No obstante, a pesar de esta situación, fueron reconocidas como miembros de la $\mathrm{ACl}^{39}$.

38 En el Congreso de Viena de 1930 se discutió un documento que contenía esta problemática que se recogería en el Congreso de París de 1937: «El memorándum declaraba que se utilizaba de un modo excesivo la referencia a los principios de Rochdale, hasta un punto que se restringía el examen de los nuevos problemas, que surgían del desarrollo incesante del comercio y de la industria, problemas que un siglo antes no presentaban el mismo aspecto ni las mismas dimensiones», WATKINS, W.P., L'Alliance Cooperative Internationale, 1895-1970, ACl, Londres, 1971, pág.183.

39 En la antigua Unión Soviética se llegó a aprobar una ley que permitió, en el año 1988, la creación de cooperativas sin intervención del Estado pero su viabilidad resultó harto complicada: «En 1988, la antigua URSS adoptó una legislación cooperativa en la que se preveía la creación de nuevas cooperativas autónomas, con una composición mínima de tres miembros, que constituyeron la primera expresión legítima de empresas privadas, pese a que sólo podían actuar en una serie restringida de sectores (proveedores de servicios y restaurantes). Ante la ausencia de mecanismos de control eficaces, esta oportunidad se utilizó en gran medida para legalizar actividades comerciales no estructuradas e ilegales, y para llevar a cabo actividades con fines lucrativos. Ahora bien, aunque se legalizaron las actividades cooperativas, las nuevas cooperativas estaban sujetas a graves restricciones, tales como impuestos elevados y medidas burocráticas heredadas de la administración comunista (por ejemplo, las restricciones a la propiedad privada de la tierra, a los préstamos, a las materias primas y a las piezas de repuesto)». Informe $V$, del quinto punto del orden del día "Promoción de las Cooperativas» de la 89a reunión de trabajo de la OIT celebrada en Junio de 2001. Conviene recordar que en 1930, en el 
El desmoronamiento del socialismo real condicionó el contenido del Congreso de Manchester de 1995 donde se propuso la inclusión novedosa del principio de Autonomía e Independencia para que la cooperativa pudiese operar, sin problemáticas de identidad, dentro de una economía de mercado capitalista ${ }^{40}$. A partir de 1995 se propicia la posibilidad de alcanzar acuerdos con cualquier tipo de empresa, siempre que se salvaguarde el principio de autonomía y el control de las operaciones de la empresa esté guiado por la gestión democrática de los socios.

\section{Bibliografia}

Añanos, M., «La doctrina de los bienes comunes de Francisco de Vitoria como fundamentación del dominio en el Nuevo Mundo», Persona y Derecho, vol. 68, 2013,1.

ARANZADI, D., Cooperativismo industrial como sistema, empresa y experiencia, Universidad de Deusto, Bilbao, 1976.

ARCO, J.L. del, «El crédito agrícola cooperativo y el informe del Banco Mundial», Revesco Estudios Cooperativos, n. ${ }^{\circ} 13,1967$

AzURMendi, J., El hombre cooperativo. Pensamiento de Arizmendiarrieta, Ed. Azazta, Otalora,

Báñez, D., Apología de los hermanos dominicos contra la Concordia de Luis de Molina, Ed. Pentalfa, Oviedo, 2002

Boltanski, L. \& ChiAPELlo, E.: El nuevo espíritu del capitalismo, Ed. Akal, Madrid, 2002

contexto del Congreso de Viena el representante soviético, I.A. Selensky consideró contrario al socialismo el reparto de excedentes o beneficios en función de las compras y abogó por la socialización o destino a bienes comunes. También se mostró crítico con el principio de neutralidad política: "los principios según el soviético debían revisarse completamente para adaptarse a los objetivos del movimiento obrero», MATEO BLANCO, J., "Historia de la reforma de los principios cooperativos», Revesco Estudios cooperativos, ISSN 0425-3485, N. ${ }^{\circ}$ 53, 1985, págs. 50-51

40 «Este principio no se recogió explícitamente en la formulación de1996. En ese momento, la $\mathrm{ACl}$ adoptó una posición más condescendiente para evitar la salida de la entidad internacional de los países de regímenes comunistas, dado que limitaban la autonomía e independencia de sus cooperativas. Ahora, tras la caída de tales regímenes, la ACl vuelve hacia la posición de 1937, época en la que consagró como uno de los principios la «neutralidad política y religiosa». Sin embargo, lo más novedoso en la formulación de este principio es la referencia a la firma de acuerdos «con otras organizaciones». Con ella se reconoce el hecho de que, en todo el mundo, cada vez más cooperativas están entrando en proyectos conjuntos con otras empresas del sector privado, aunque se señala la importancia de que éstas mantengan la libertad de controlar su propio destino futuro al negociar tales acuerdos». GADEA SOLER, E., «Estudio sobre el concepto de cooperativa: Referencia a los principios cooperativos y su discutida vigencia», JADO: boletín de la Academia Vasca de Derecho, n. ${ }^{\circ}$ 17, año 7, 2009, págs.168-185, p. 181. 
CASAdo, I., Diccionario de Economía Social, Ed. Ecoobook, Madrid, 2009

FourIER, Ch. Teoría de los cuatro movimientos y de los destinos generales, Ed. Barral, 1974

GAMINDE, E., La doctrina social cristiana y el cooperativismo vasco; una alternativa para el cambio, Ed. Dykinson, Madrid, 2017

García Muñoz, Q., Cooperativismo y desarrollo, Ed. Marsiega, Madrid, 1973

Gascón y Miramón, A., La cooperación y las cooperativas, Madrid, 1954

HERTLING, L., Historia de la Iglesia, Ed. Herder, Barcelona, 1993

INGLADA, M.E. y otros, "El cooperativismo en la educación», Revesco Estudios

Cooperativos, Universidad Complutense de Madrid, n. ${ }^{\circ} 118$

JIMÉNEZ, R., «El modelo didáctico de las técnicas Freinet: una síntesis práctica de

los principios básicos contemporáneos», Revista de educación Tavira, Universidad de Cádiz, 1987

LASSERRE, G., El cooperativismo, Ed. Oikos-tau, Barcelona, 1972

LENIN, V.I., "Sobre la cooperación», Tareas de las juventudes comunistas, Obras

Escogidas en 12 vol., Tomo 3, Editorial Progreso, Moscú, 1961

LUTERO, M., Escritos políticos, Ed. Tecnos, Madrid, 1986

MARín, I., LABRADOR, O. y MiRABAL, Y., «La educación cooperativa como eje cen-

tral para la formación integral en el sector cooperativo», Cooperativismo y Desarrollo, Vol. 1, Cuba, 2013

Martinez Charterina, A., La cooperativa y su identidad, Ed. Dykinson, Madrid, 2016

MARTínez-Soto, A.P., «Los orígenes del cooperativismo de crédito agrario en España, 1890-1934), Revista CIRIEC-España de Economía Pública, Social y Cooperativa, n. ${ }^{\circ} 44,2003$

MarX, K., El Capital, Tomo III, F.C.E., México, 1968

Nove, A., Historia Económica de la Unión Soviética, Ed. Alianza, Madrid, 1973

Orozco, J., Antología doctrina cooperativa, Ed. Universidad Estatal a Distancia,

San José de Costa Rica, 1986

Piaton, G., El pensamiento pedagógico de Celestino Freinet, Ed. Marsiega, Madrid, 1975

SaINT Simon, H., El nuevo cristianismo, Ed. Biblos, Buenos Aires, 2004

SANTOS, L.M., Robert Owen, pionero del management. [Documentos de Tra-

bajo de la Facultad de Ciencias Económicas y Empresariales; n. ${ }^{\circ}$ 27, 2000,

SuAREZ, F., De legibus, CSIC, Madrid, 1981

WATKINS, W.P., L'Alliance Cooperative Internationale, 1895-1970, ACI, Londres, 1971

WeBer, M., La ética protestante y el espíritu del capitalismo, Ed. Península, Barcelona, 1988 